\title{
A enfermagem na ressignificação da vida diante da enfermidade
}

\author{
Nursing in life resignification on face of disease \\ El oficio de enfermero en la resignificación de la vida delante de la enfermedad
}

\section{Lucilda Selli \\ Doutora em Ciências na Saúde Pública Professora e Pesquisadora no PPG em Saúde Coletiva - Universidade do Vale do Rio dos Sinos (UNISINOS)}

Eloir Antonio Vial

Acadêmico de Enfermagem. Bolsista PROBIC/FAPERGS

UNISINOS

José Roque Junges

Doutor em Ciências da Saúde/Bioética. Professor e Pesquisador no PPG em Saúde

Coletiva - UNISINOS

\section{RESUMO}

O texto trata do papel educativo do trabalhador da saúde. As idéias expostas são frutos da reflexão que se deu a partir de uma pesquisa sobre a ressignificação da vida de indivíduos acometidos por doenças que sugerem mudanças no seu modo de viver. O trabalhador da saúde tem um papel fundamental nesse processo, influenciando o paciente positiva ou negativamente. A reflexão aborda o processo subjetivo de ressignificação da vida na situação saúde/doença e o papel educacional do profissional de enfermagem no desempenho de suas competências. 0 ensino/aprendizagem influencia na configuração do imaginário do indivíduo, desse modo, constituindo um importante ingrediente no saber/fazer educação no exercício profissional.

Descritores: Assistência ao paciente; Educação do paciente; Ensino.

\section{ABSTRACT}

The paper deals with the educational role played by the health care provider. The ideas exposed stem from a reflection made from a research on the resignification of life of individuals affected by diseases that entail changes to their lifestyle. The health care provider has a key role in this process, influencing the patient positively or negatively. The reflection approaches the subjective process of life resignification in the health/disease situation and the educational role of the nursing professional in performing their tasks. Teaching and learning influence the configuration of the individual's imagery, constituting thereby an important ingredient to the educational know-how in the professional practice.

Descriptors: Patient care; Patient education; Teaching.

RESUMEN

El texto trata del papel educativo del trabajador de la salud. Las ideas mostradas son frutos de la reflexión, resultantes de una investigación sobre la resignificación de la vida de los individuos que poseen enfermedades que requieren cambios en su forma de vivir. El trabajador de la salud posee un papel fundamental en ese proceso, haciendo influjo en el paciente positiva o negativamente. La reflexión discute el proceso subjetivo de la resignificación de la vida en la situación salud/enfermedad y el papel educacional del profesional del oficio de enfermero en el desempeño de sus competencias. El enseño/aprendisaje influye en la configuración del imaginario del individuo, de esa manera, constituyendo un importante ingrediente en el saber/hacer educación en el ejercicio profesional.

Descriptores: Atención al paciente; Educación del paciente; Enseñanza.

Selli L, Vial EA, Junges JR. A enfermagem na ressignificação da vida diante da enfermidade. Rev Bras Enferm 2005 jan-fev; 58(1):82-5.

\section{INTRODUÇÃO}

O trabalho no campo da saúde sofreu grandes transformações por influência de reformas sanitárias acontecidas na década de 90 e, também, como decorrência das transformações estruturais ocorridas por causa dos processos de globalização e integração econômica, da evolução demográfica e epidemiológica, do desenvolvimento tecnológico, dos novos atores que entraram em cena e devido às mudanças nos paradigmas em saúde pública(1). As reformas querem responder a perfis mais complexos de saúde, exigindo estratégias de intervenção mais audazes orientadas a modificar as condições de vida, as iniqüidades e os comportamentos individuais e coletivos ${ }^{(2)}$.

A ressignificação é um processo de subjetivação pelo qual a pessoa se apropria da sua doença, levando a um reordenamento, mudança e nova concepção de vida para se situar no atual contexto existencial provocado pela doença. É nesse universo existencial que a pessoa/doente é visitada e re-visitada pela inquietação gerada pela nova situação vivencial. A percepção e apropriação desta realidade, interpenetrada de campos de sentido afetivo-existencial, auxiliam no sentido de redefinir e reorganizar continuamente seu horizonte de significação, seu sentido vital(3).

O processo de ressignificação da vida frente à situação de doença é entendido como a capacidade de "modificar o molde pelo qual uma pessoa percebe os acontecimentos, a fim de alterar o significado. Quando o significado se modifica, as respostas e comportamentos da pessoa também se 
modificam"(4). Esta é influenciada pelo ambiente sociocultural e pela atitude do profissional da saúde. A reflexão recolhe um viés teórico de análise - 0 papel educativo do trabalhador da saúde - dos dados coletados em entrevistas semi-estruturadas, com sujeitos enfermos crônicos, baixados em um hospital da grande Porto Alegre (RS), e suas reações diante da doença.

Assim, a produção do artigo sobre o papel do profissional da saúde como educador no processo de ressignificação da vida frente à doença originou-se da constatação de que este tem um papel importante na subjetivação do processo saúde/doença, sendo um fator marcante nessa construção.

\section{CONTEXTO E SITUAÇÃO DO TRABALHADOR EM SAÚDE}

As tecnologias aplicadas à saúde predominam no tratamento da doença e no processo da cura, trazendo benefícios e suscitando expectativas cada vez mais promissoras, porém, em muitas situações, são irreais para as pessoas vitimadas pela doença. Portanto, constituem um elemento cada vez mais presente no processo de ressignificação, visto que a mentalidade técnica configura sempre mais o próprio contexto sociocultural. Embora as tecnologias da saúde abram perspectivas positivas para os usuários, elas não penetram o âmago das questões humanas existenciais mobilizadas, sobretudo, em situações de vulnerabilidade, como é o caso da doença(5).

Por sua vez, o crescente uso de tecnologias, associado à visão mecanicista, que percebe o corpo humano como uma máquina constituída de órgãos, peças, etc., força o profissional da saúde a avançar, sucessivamente, em campos específicos de especialização. Essa exigência é influenciada não apenas pela resposta tecnológica, mas, ao mesmo tempo, pelo ponto de vista que percebe a doença e não 0 ser humano doente. A especialização, ao mesmo tempo em que aprofunda um conhecimento, encaminha-se a uma fragmentação do saber e do próprio paciente. Em lugar de tratar a pessoa doente, 0 especialista tende a tratar a patologia de sua especificidade ${ }^{(6)}$. Este fato favorece um domínio específico de saber técnico/prático, entretanto, limita o profissional no sentido de desenvolver uma visão integral da saúde humana.

Na década de $70^{(7)}$, já se alertava sobre a substituição do médico artesão, com habilidades fundadas no conhecimento pessoal dos indivíduos, pelo médico técnico, que aplica regras científicas a categorias de doentes. $O$ que antes era considerado abuso de confiança e transgressão da moralidade, agora, pode ser racionalizado como falha técnica ocasionada pelos equipamentos ou por seus operadores.

A falta de uma relação mais empática pela redução da prática a um exercício predominantemente técnico não permite ao trabalhador da saúde ser um mediador do necessário processo de subjetivação do usuário. É importante que ele compreenda esse movimento de ressignificação de subjetividade frente à doença. Considerar o significado para a promoção da saúde, estando atento à influência do ambiente sociocultural e ao seu papel na seqüência de situações vivenciais envolvidas no processo de ressignificação. Nesse sentido, o profissional de enfermagem, no seu papel de educador, ajuda a pessoa, em situação de doença, a interpretar e reinterpretar sucessivamente a sua própria doença, levando-o a familiarizar-se ${ }^{(8)}$ com 0 novo, possibilitando ao usuário criar condições de agir consciente no processo de ressignificação da vida frente à doença.

\section{A DIALÉTICA INDIVÍDUO/SOCIEDADE}

As relações entre o indivíduo, considerado em sua complexidade, e o social - entendido como representação social e coletividade social no processo de saúde/doença, não são facilmente percebidas e compreendidas pelos indivíduos, tanto profissionais quanto pacientes. A própria percepção da saúde ou da doença é influenciada pela posição social e pela cultura do grupo social de referência do indivíduo(8). 0 processo educativo implica perceber o indivíduo/sujeito inserido em um determinado contexto sociocultural e os significados representativos, assimilados pelo mesmo como construções de vida/saúde/doença. A doença, como fenômeno intimamente ligado à vida privada dos indivíduos, é, raramente, um caso isolado(9).
Outro aspecto é a autonomia, que, expressa pelo indivíduo que se apropriou de sua realidade, é entendida, neste contexto, não como liberdade absoluta, emancipada de qualquer dependência, mas como autonomia em dependência do seu meio ambiente, seja ele biológico, cultural ou social(10). Ou seja, trata-se de uma autonomia entendida como sujeito que integra e interage no ambiente e com o ambiente em suas diferentes formas de expressão. O profissional da enfermagem tem 0 desafio de investir na construção conjunta de um projeto que englobe a complexidade e a multidimensionalidade das necessidades de saúde. Trata-se de articular os saberes e as ações de outros âmbitos da produção do cuidado, tais como educativo, preventivo, psicossocial, comunicacional, que aparecem como periféricos ao trabalho nuclear da assistência médica individual(11). Além de articular os diferentes saberes, o trabalhador da saúde, como sujeito mediador no processo de ressignificação, é interpelado a desenvolver competências que possibilitem um olhar para a pessoa em sua existência total(5), isto é, compreendendo o ser humano em sua integralidade e não apenas como portador de doença.

A apropriação da saúde e da doença, a partir de construções de sentido, implica um processo de subjetivação. Essa construção tem a ver com as representações culturais presentes no contexto social. Os seres humanos interpretam suas experiências a partir de referências simbólicas presentes nos significados socialmente aceitos ${ }^{(12)}$. Daí a importância de conjugar a dialética indivíduo/sociedade no processo saúde/doença/ressignificação. Este processo implica uma postura de desnaturalização das situações tidas, rotineiramente, como normais, no saber/fazer profissional, possibilitando, deste modo, espaço para a problematização das situações permeadas nas práticas cotidianas. Esse distanciamento crítico caracteriza um momento de conscientização e, portanto, uma atitude profissional ética e educativa.

\section{O PROCESSO DE SUBJETIVAÇÃO}

A construção de políticas de educação em saúde, pautadas pelo compromisso com a defesa da vida, não pode minimizar o papel dos processos nos quais as subjetivações se produzem e reproduzem. Intervir nas organizações significa intervir nas construções de sentido. Uma questão candente está relacionada às organizações, cuja questão é o que fazer com as mesmas uma vez que a essência destas são também a essência de seus trabalhadores ${ }^{(13)}$. Avançando nesta discussão(14), ao adentrar a micropolítica do trabalho vivo em saúde, enfatiza que mexer em processos de trabalho é mexer com cabeças e interesses, ou seja, é mexer em subjetivações.

A subjetividade tem consistência e sentido em um mundo infinitamente plural apenas e na medida que se compõe pluralmente ${ }^{(3)}$, ou seja, é na relação que se constrói e reconstrói a subjetividade. Dessa forma, o trabalhador da saúde, pelo seu saber/fazer profissional, constitui elemento chave para o indivíduo/sujeito, contribuindo no re-apropriar dos componentes da subjetividade e instaurar processos de ressignificação.

Para entender a subjetividade consideramos as idéias dos biólogos Maturana e Varela(15), os quais revolucionaram a compreensão dos seres vivos ao proporem a definição de sua identidade não mais a partir de características morfológicas, mas de sua organização autopoiética. Qualquer sistema vivo conforma-se como autopoiese, pois está capacitado a reordenar seus componentes numa nova organização quando sofre perturbações. Nesse sentido, a autopoiese é a capacidade de reagir de todo ser vivo.

Assim, o que caracteriza um ser vivo não é apenas os seus componentes ou a soma deles, mas inclusive a forma própria de organizá-los devido à sua capacidade autopoiética. Essa autoorganização depende da interação do ser vivo ao seu ambiente. O ser vivo morre quando perde essa capacidade auto-organizativa, porque não consegue fazer frente à desordem provinda do meio ao qual está ligado(16).

O ser humano detém uma organização autopoiética muito mais complexa por ser um ente ao mesmo tempo biocultural provido de linguagem e consciência. A autopoiese humana significa uma 
complexificação da capacidade de reordenar seus componentes em uma nova organização. Saúde significa autopoiese; doença um ataque à organização autopoiética. Neste sentido, saúde não pode ser definida ou caracterizada simplesmente pela presença de certos componentes, contudo pela capacidade de auto-ordenar, re-ordenar esses componentes em uma nova composição existencial. Essa capacidade autopoiética identifica-se com o processo de subjetivação e é influenciada pelas representações culturais e pelo contexto social. Por isso, no ser humano, a organização autopoiética tem uma complexidade que engloba as dimensões: somática, psíquica, social, cultural e espiritual. O funcionamento da organização autopoiética depende do seu acoplamento ao ambiente.

Além da organização autopoiética (biológica), o ser humano é constituído de um conjunto de processos sociais e intrapsíquicos, a resiliência, ou seja, "... a capacidade do ser humano para fazer frente às adversidades da vida, superá-las e, inclusive, ser transformado por elas"(17). A capacidade reativa depende dos recursos fornecidos pelo meio que, para o ser humano, é essencialmente sociocultural. 0 profissional da saúde ocupa um papel de destaque no fornecimento de recursos para autopoise e resiliência, substanciais para o processo de ressignificação.

\section{COMPETÊNCIAS PARA AS PRÁTICAS EDUCATIVAS EM SAÚDE}

Ainda consideramos que, enquanto componente das representações sociais do sujeito/paciente/usuário, o trabalhador da saúde é parte integrante nas compilações imaginárias, não-familiares e de um universo reificado ${ }^{(8)}$, que, no entanto, são as próprias bases constituintes para a familiarização e o universo consensual deste sujeito.

A prática supõe também atitudes e posturas mentais, curiosidade, paixão, busca de significado, desejo de tecer laços, relação com o tempo, maneira de unir intuição e razão, cautela e audácia, que nascem tanto da formação como da experiência. 0 conhecimento está presente em quase todas as ações humanas, às vezes de maneira superficial; outras vezes, aprofundada e, quanto mais elas forem complexas, abstratas, mediatizadas por tecnologias e apoiadas em modelos sistêmicos da realidade mais conhecimentos aprofundados, avançados, organizados e confiáveis elas exigem ${ }^{(18)}$.

Dessa forma, as alterações produzidas por esse modelo educativo provocam um deslocamento de noções: dos saberes à competência na esfera educativa; da qualificação à competência na esfera do trabalho ${ }^{(19)}$. A atuação em saúde, respaldada por competências e com respostas educacionais adequadas, supõe ações, avaliações e redefinições permanentes, acompanhadas pela constante qualificação.

\section{CONSIDERAÇÕES FINAIS}

Os determinismos históricos e culturais do ensino marcam fortemente a formação dos profissionais da saúde. O modelo de ensino assenta-se substancialmente no fator biológico do ser humano, com preocupação na resolução dos problemas fisiológicos do paciente. $\mathrm{O}$ objeto de trabalho dos profissionais da saúde ainda é a doença. É, em torno dela, que são elaborados os conhecimentos com uma dicotomia marcante entre 0 papel educativo e curativo. 0 ensino, na área da saúde, evidencia dois componentes inseparáveis: o processo de ensino e as suas relações. Isso, colocado em prática, leva a crer que, dentro de alguns anos, as escolas estarão graduando profissionais da saúde mais criativos, solidários, críticos e competentes ${ }^{(20)}$.

Há a necessidade da articulação político-pedagógica que viabilize a formação profissional voltada para as necessidades da população a partir da construção de projetos político-pedagógicos. Estes, com vistas a possibilitar a formação de profissionais capazes de buscar constantemente o conhecimento para solucionar os problemas que se apresentam das mais diversas formas, devem estar voltados a uma construção de competências a fim de se apropriarem e transformá-las num processo crítico reflexivo.

Nas instituições educacionais, permanece a falta de coerência ${ }^{(21)}$ enquanto sistema de educação. O corpo docente não está voltado para desenvolver competências no corpo discente, isso porque leva em consideração ainda o biológico com maior ênfase, deixando à margem a integralidade. Assim, o profissional da saúde, como educador, não poderá contribuir com o usuário na construção progressiva de uma vivência coerente e integral. Tal fato somente se dará quando levar em consideração as diversas esferas, e que vão além do biológico na composição do paciente: o imaginário, as expectativas, o conhecido e 0 desconhecido, a subjetividade, as representações sociais, o familiar e não-familiar ${ }^{(8)}$. É necessário, então, que o profissional atue com competência na implementação do saber/fazer enfermagem.

Dessa forma, o planejamento participativo constitui um instrumental de não acomodação do educador e visibilizador na proposta pedagógica na relação (pré) professor/aluno; e (pós) profissional/paciente no compromisso, no desejo, na competência, podendo ajudar até a apontar onde a matéria-prima e a energia precisam ser melhoradas ${ }^{(22)}$. 0 processo educativo transversalizado implica perceber o indivíduo/sujeito inserido em um determinado contexto sociocultural e os significados representativos assimilados pelo mesmo em suas construções de vida/ saúde/doença.

É evidente o papel do profissional da saúde/educador inserido no mercado de trabalho, do profissional criativo, ocupado com as transformações dos serviços e competente para conduzir estas transformações. É imprescindível investir na construção conjunta de um projeto educativo/assistencial que abarque a complexidade e a multidimensionalidade das necessidades de saúde, que perpassa e ultrapassa 0 aspecto curativo e contemple 0 existencial em jogo no processo de ressignificação. Trata-se de articular os saberes e as ações de outros âmbitos da produção do cuidado, tendo em vista a pessoa como um ser inteiro e não apenas como um indivíduo portador de uma doença. A educação qualifica 0 atendimento e constitui ingrediente fundamental no processo de ressignificação, dessa forma, ajudando a pessoa a fazer frente à própria fragilidade e enfrentar com propriedade as instabilidades a que, como humanos, somos submetidos.

\section{REFERÊNCIAS}

1. OPS. Funciones esenciales de salud publica: una perspectiva desde las práticas sociales. Marco de referência para uma discusión regional. Washington, 1998 jul.

2. OPS. División de Desarollo de Sistemas y Servicios de Salud Funciones esenciales de salud publica. Documento de Posición. Washington, 1997 jul.

3. Souza TR. Ainda além do medo. Porto Alegre (RS): Dacasa; 2002.

4. Bandler R, Grinder J. Sapos em príncipes: programação neurolinguística. Trad. Maria Sílvia Mourão Netto. $6^{\text {a }}$ ed. São Paulo (SP): Summus; 1982.

5. Bellino F. Fundamentos da Bioética. São Paulo (SP): EDUSC; 1997

6. Martin ML. A Ética e a humanização hospitalar. Mundo da Saúde 2003;27:206-17.

7. Illich I. A expropriação da saúde. Nêmesis da Medicina. Rio de Janeiro (RJ): Nova Fronteira; 1975.

8. Moscovici S. Representações sociais: investigações em psicologia social. Trad. Pedrinho Guareschi. Petrópolis (RJ): Vozes; 2003.

9. Berlinguer G. A doença. São Paulo (SP): HUCITEC; 1998.

10. Morin E. A cabeça bem-feita: repensar a reforma reformar o pensado. Rio de Janeiro (RJ): Bertrand Brasil; 2002.

11. Peduzzi M. Multiprofessional healthcare team: concept and typology. Rev Saúde Pública 2001 fev;35(1):103-09.

12. Minayo MCS. O desafio do conhecimentos. Pesquisa qualitativa em

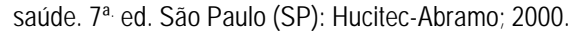

13. Testa M. Analisis de instituiciones hipercomplexas. In: Mehry EE Onocko R, org. Agir em saúde - um desafio para o público. $2^{\text {a. ed. }}$ ed. São Paulo (SP): HUCITEC; 2002. p. 260.

14. Mehry EE. Em busca do tempo perdido: a micropolítica do trabalho vivo em saúde. In: Mehry EE, Onocko R, org. Agir em saúde - um desafio para o público. 2a. ed. São Paulo (SP): HUCITEC; 2002. p. 125. 
15. Maturana R, Varela García FJ. De máquinas e seres vivos: autopoiese - a organização do vivo. Porto Alegre (RS): Artes MÉdicas; 1997.

16. Morin E. O Método. O conhecimento do conhecimento. Porto Alegre (RS): Editora Sulina; 1999.

17. Grotberg EH. In Melillo A, Ojeda ENS. Resiliéncia: decubriendo las proprias fortalezas. Buenos Aires (AR): Paidós; 2003.

18. Perrenoud P. Construir as competências desde a escola. Porto Alegre (RS): Artmed; 1999.
19. Desaulniers JBR. Formação, competência e cidadania. Educ Sociedade 1997: 51-63.

20. Almeida MJ. Tecnologia e medicina: uma visão da academia. Bioética 2000;8(1):69-78.

21. Perrenoud P. Dez novas competências para ensinar. Trad. Patrícia Chittoni Ramos. Porto Alegre (RS): Artes Médicas Sul; 2000.

22. Vasconcellos CS. Planejamento: Projeto de Ensino-Aprendizagem e Projeto Político Pedagógico - elementos metodológicos para elaboração e realização. 10a. ed. São Paulo (SP): Libertad; 2002. 